\title{
Adoption and consistency of application of premilking preparation in Ontario dairy herds
}

\author{
E. Belage, ${ }^{*} \dagger$ S. Dufour, † D. A. Shock, $\S$ A. Jones-Bitton, ${ }^{*}$ and D. F. Kelton* ${ }^{*}{ }^{1}$ \\ *Department of Population Medicine, University of Guelph, Guelph, Ontario, Canada, N1G 2W1 \\ †Canadian Bovine Mastitis and Milk Quality Research Network, C.P. 5000, St-Hyacinthe, Quebec, Canada, J2S 7C6 \\ ‡Department of Pathology and Microbiology, Faculty of Veterinary Medicine, University of Montreal, C.P. 5000, St-Hyacinthe, Quebec, Canada, \\ J2S 7 C6 \\ §Upper Grand Veterinary Services, Main Street Animal Hospital, Cambridge, Ontario N1R5S7, Canada
}

\begin{abstract}
Milking management practices that affect udder health have been widely studied, leading to a variety of evidence-based recommendations. Lack of adoption or inconsistency in milking practices can interfere with efforts to prevent mastitis in the herd. The study objective was to assess the variation in adoption and application consistency of important milk harvest practices between and within farms over time. During the summer of 2013, 50 herds in southern Ontario were visited twice within a month, at milking time, and a single person observed and time-recorded premilking preparation procedures. A generalized mixed model was used to partition the variance for predisinfectant contact time and preparation lag time (time between the first contact with the teats and cluster attachment), and determine the proportion of variation attributable to farms, milkers, visits, and characteristics of a cow milking. Using logistic regression, models were built to assess factors affecting adequate contact time and adequate preparation lag time, respectively. Farm, the person(s) milking, and visit number were used as random effects in both instances. In both models, farm-to-farm differences and variations between cows during a specific milking accounted for the largest part of the variability seen in both contact time (47 and $44 \%$, respectively) and preparation lag time (40 and $36 \%$, respectively). For both outcomes, milkers were consistent in their routines over the 2 visits (only 9 and $3.1 \%$ of total variance for contact and preparation lag time, respectively). Parlors were more likely to meet the recommended contact time than tie-stalls; increased number of milkers at milking time and having contact times under $30 \mathrm{~s}$ had negative
\end{abstract}

Received July 5, 2016.

Accepted January 17, 2017

${ }^{1}$ Corresponding author: dkelton@uoguelph.ca effects on meeting recommended preparation lag time. The majority of farms in the study complied with the recommendations for adequate milking practices; however, most did not follow a consistent timed protocol. There are several potential sources of variation in the milking routine on a dairy farm. To improve milk quality and udder health, it is important to identify whether best management practices are being implemented on each farm. Producers appeared to be consistent in the application of milking procedures across time, regardless of whether or not they were correct. Hence, with corrective education and training, improvements in these practices could be experienced and maintained to promote better udder health.

Key words: udder health, milking practices, contact time, preparation lag time, variation in milking preparation

\section{INTRODUCTION}

The management practices and milking procedures that affect mastitis and SCC have been widely studied, leading to a variety of evidence-based recommendations; however, the evidence for many of these recommended procedures is scarce. An invited review by Dufour et al. (2011) evaluated which practices were consistently associated with SCC on farms, and which lacked evidence of an association with SCC. Some of the practices having consistent associations with SCC include wearing gloves at milking time, using a single-cow towel to dry teats, use of a pre- and postmilking teat disinfectant, and dry cow treatment (Dufour et al., 2011). Based on the body of research available, the National Mastitis Council (NMC) published a set of recommended milking procedures for dairy farmers to follow (NMC, 2013). These recommendations include using a premilking teat disinfectant, cleaning and drying teats before unit attachment, having an adequate delay (i.e., preparation lag time) between teat stimulation and milking unit attachment, and using a postmilking teat disinfectant. 
A study of 80 large dairy farms in Germany between 2001 and 2002 found that methods employed on different farms, as well as consistency in milking methods within a farm, varied substantially (Köster et al., 2006). The study found an association between the attentiveness of people milking (measured by looking at cleanliness and consistency of milking practices), and overall herd SCC in each farm during the month of the farm visit. Most study farms practiced foremilk stripping and postmilking teat disinfection. The consistency with which these practices were applied, however, varied between milkers on a farm (Köster et al., 2006). The study also found that the detection of cases of clinical mastitis was lacking in $32 \%$ of participating herds, again with inconsistencies in detection accuracy among milkers within the same farm. This inconsistency was potentially due to differences in the definition of clinical mastitis among milkers.

Other farm-level factors affecting bulk tank SCC include the number of people involved in milking, and the level of familiarity the producers have with their cows. In one study, farms with fewer people involved in the milking process had lower bulk tank SCC than herds with more people milking; this effect was hypothesized to be due to the individual's familiarity with the process as they milked more frequently (Barnouin et al., 2004). Farmers who considered themselves "meticulous" and "tidy" had herds with lower bulk tank SCC (Barkema et al., 1999; Barnouin et al., 2004). Herds with bulk tank SCC that could be considered "medium" (mean SCC of 265,000 cells/mL) usually had milkers who were less skilled or less careful than herds with low bulk tank SCC (mean SCC of 135,000 cells/mL; Chassagne et al., 2005). To our knowledge, no studies have investigated a potential relationship between herd size and the milkers' skills and attention to detail. Larger dairy farms tend to have more hired (nonfamily) help and could have training in standard operating procedures, whereas smaller farms are more likely to be family operated with less formal training. Also, no studies have been published evaluating the rate of adoption or the consistency of milking preparation procedures over time. It is important to address these knowledge gaps because despite having recommendations for producers, it is not known whether they are following the guidelines correctly or consistently (or both). Lack of adoption or inconsistency in milking practices likely affects udder health, and it can directly or indirectly interfere with efforts to prevent mastitis in the herd. Therefore, the objective of this study was to assess the variation in adoption, and consistency in application, of important milk harvest practices between and within farms over time.

\section{MATERIALS AND METHODS}

Ethical approval was obtained through the Research Ethics Board at the University of Guelph (REB\#13FE005), and all participants provided informed, written consent.

\section{Data Collection Protocol}

Farm Selection. This study was part of a larger project investigating the effect of environment, management, and pathogen burden on the late summer rise in bulk tank SCC by Shock (2014). Herds were selected using milk quality records routinely collected by the Dairy Farmers of Ontario (DFO), an organization that markets milk on behalf of Ontario dairy producers. Farm-level criteria required for inclusion in the study were as follows: owning more than $30 \mathrm{~kg}$ of butterfat quota, participating in milk recording with CanWest DHI (a nonprofit milk recording organization) at a service level including 9 or more herd tests per year, and having a monthly bulk tank SCC average between 150,000 and 250,000 cells/mL as of January 2013. This range was chosen as it closely represents the middle two-thirds of the herds in the province of Ontario for that month: approximately $60 \%$ of herds fell in the range of 150 to 250,000 cells $/ \mathrm{mL}$. For the purpose of the original study, typical herds were being studied instead of extremes. Out of a list of 452 herds meeting the eligibility criteria, 50 herds were recruited by convenience sampling based on the resources available for the project (Shock, 2014).

Milking Procedures. Each of the 50 herds was visited twice over a 1-mo period during the summer of 2013 (June through August) at milking time. At this time, the producer completed a version of the udder health questionnaire validated by Dufour et al. (2010), and a single person observed and time recorded various milking procedures using a manual stopwatch. The procedures of interest were milking hygiene and preparation procedures, including contact time (time between application and removal of the premilking teat disinfectant solution), and preparation lag time (Shock, 2014). Because the measure of preparation lag time was highly variable depending on each farm's routine, for the purposes of this study preparation lag time was defined as the time between the first contact with the teats (wiping, predipping, or start of forestripping) and cluster attachment. The person observing the milking recorded the order of each milking procedure, the number of milkers present at the time, as well as their names. During each visit, a convenience sample of 10 to 15 animals was selected from the entire milking herd, 
Table 1. Structure of data for contact time of premilking disinfectant in 50 Ontario dairy herds visited twice over the summer of $2013^{1}$

\begin{tabular}{lccc}
\hline & & \multicolumn{2}{c}{ No. of units per highest cluster level } \\
\cline { 2 - 3 } Level & No. of observations & Mean & Range \\
\hline Farms & 41 & - & $-1-5$ \\
Milkers & 91 & 2.2 & $1-2$ \\
Visits & 119 & 1.3 & $1-20$ \\
Cow milking & 1,138 & 9.6 & \\
\hline${ }^{1} 69.2 \%$ of milkers were only observed during one visit. &
\end{tabular}

${ }^{1} 69.2 \%$ of milkers were only observed during one visit.

distributed through the entire milking at each visit, and the procedures were timed for those particular animals.

\section{Statistical Analysis}

All statistical analyses were completed using SAS version 9.4 (SAS Institute Inc., Cary, NC). Descriptive statistics were computed for all variables of interest to assess frequencies and distributions, as well as to identify improbable values. Values that were deemed improbable (including negative time intervals) were considered to be recording or transcription errors and were set as missing. Normality of continuous variables was assessed using both graphical methods and the Shapiro-Wilk test. Correlation between variables was assessed by computing Spearman and Pearson coefficients (PROC CORR), and odds ratios for binary variables (PROC FREQ) to identify highly correlated variables. Variables were considered collinear if the correlation coefficient was higher than 0.5 or lower than -0.5 , or if the odds ratio was greater than 10.0 , or smaller than 0.10 . If 2 variables were highly correlated, the variable of highest interest was kept for inclusion in statistical model development.

\section{Regression and Structure of the Data Set}

Two outcomes were modeled independently: time between premilking teat disinfectant application and removal, defined as "contact time," and time between the beginning of first contact with the teats and milking unit attachment, defined as "preparation lag time."

To investigate consistency of implementation of contact time and preparation lag time between farms, milkers, visits, and individual cow milkings, a null model (i.e., a model without predictors) was first used for partitioning of the variance between levels (farm, milker, visit, and a cow milking) as described by Dohoo et al. (2009). A 4-level hierarchical model with the previously described structure was used for the preparation lag time analysis. The contact time data set, however, consisted of a subset of the 50 herds (i.e., the 41 herds that were using premilking teat disinfection). In this latter smaller data set, complete separation of the data precluded use of the full 4-level structure. For the contact time analysis, a cross-classified hierarchical model with individual cow milking cross-classified by both milkers and visits, which were, in turn, clustered by herds was therefore used (Tables 1 and 2). Because of this feature, disentangling the variation in contact time due to characteristics of milkers and visits was not possible in this model and had to be reported as a whole (i.e., the combination of characteristics of milkers and visits). The MIXED procedure of SAS 9.4 was used for these analyses.

Factors associated with the probability of having a successful preparation lag time or a successful contact time were then investigated. For this purpose, the dependent variables were converted to binary variables. Contact time was deemed adequate, or equal to 1 ,

Table 2. Structure of preparation lag time data in 50 Ontario dairy herds visited twice over the summer of 2013

\begin{tabular}{lccc}
\hline & & \multicolumn{2}{c}{ No. of units per highest cluster level } \\
\cline { 3 - 4 } Level & No. of observations & Mean & Range \\
\hline Farms & 50 & - & -7 \\
Milkers & 114 & 2.3 & $1-2$ \\
Visits & 152 & 1.3 & $1-20$ \\
Cow milking & 1,447 & 9.5 & \\
\hline
\end{tabular}

${ }^{1} 66.7 \%$ of milkers were only observed during one visit. 
Table 3. Overall herd characteristics of 50 Ontario dairy herds participating in a study on adoption and consistency of milking procedures

\begin{tabular}{lrrr}
\hline Variable & Average & Minimum & Maximum \\
\hline Herd size (no. of cows) & 76 & 27 & 340 \\
Monthly weighted average bulk tank SCC (cells/mL) & 252,000 & 95,000 & 562,000 \\
Milking units, parlor (n = 24; units) & 13 & 4 & 20 \\
Milking units, tie-stall (n = 26; units) & 5 & 3 & 9 \\
People milking, parlor (no.) & 1 & 1 & 3 \\
People milking, tie stall (no.) & 2 & 1 & 3 \\
\hline
\end{tabular}

if contact time was $\geq 30 \mathrm{~s}$ based on published $\mathrm{NMC}$ guidelines (NMC, 2013). Contact time $<30$ s was deemed inadequate or equal to 0 . Preparation lag time was categorized as adequate, coded as 1 , if time was $\geq 60 \mathrm{~s}$, or inadequate, equal to 0 , if time was $<60 \mathrm{~s}$. The NMC guidelines recommended a preparation lag time between 60 and $120 \mathrm{~s}$ (NMC, 2013). This categorization was based on studies that showed a short preparation lag time led to an increased milking unit on time and decreased flow rates, whereas the opposite effect was seen when lag time was increased beyond $60 \mathrm{~s}$ up to 240 s (Watters et al., 2012).

For both outcomes, the probability of observing the adequate behavior was modeled using generalized linear mixed models with a logit link using the GLIMMIX procedure of SAS 9.4. Farm, milker, and visit number were included as random effects in the preparation lag time analyses, whereas farm and milker-visit (i.e., the cross-classification term) were used in the contact time analyses. Due to the exploratory nature of this study, only unconditional associations between exposures and outcomes were investigated. Various predictors were, therefore, added to the model one at a time as fixed effects. Predictors under investigation were chosen using a causal diagram developed for each outcome to identify the possible relationships between variables at hand and the outcome. Variables assessed as potential explanatory fixed effects included milking system (parlor vs. tie-stall), herd size, use of forestripping in the milking routine, type of milking routine (single vs. multi-step), number of milking units, total number of milkers on farm, number of units per milker, and number of units per 100 cows. Quantitative variables were categorized based on quartiles for the analysis because most did not meet the linearity assumption. Adequate contact (yes/no) was also tested as a fixed effect in the preparation lag time model to determine if farms with adequate contact time were more likely to have adequate preparation lag time. Least squares means were calculated for categorical variables to obtain odds ratios between categories and Tukey-Kramer adjustment was used for multiple comparisons.

\section{RESULTS}

\section{Descriptive Statistics}

The overall herd characteristics of the 50 farms are presented in Table 3. The proportion of number of milking units per 100 cows in parlor and tie-stall herds is presented in Table 4 . The overall adoption of best milking practices in all herds is summarized in Table 5, and the contact and preparation lag time parameters are presented in Table 6 . On average, herd size in this study was 76 cows, and farms had a weighted average bulk tank SCC of 252,000 cells/mL. In this study, 26 herds $(52 \%)$ in this were tie-stalls, and 24 herds (48\%) had parlors; the average number of milkers at one time was 2 people for tie-stall herds and 1 person for parlor herds.

\section{Mixed Model and Variance Partitions}

Contact Time. The covariance parameter estimates from the mixed model analyses of adequate contact time are presented in Table 7 . The largest source of variation was due to differences between farms ( $47 \%$ of total variation), and very little variation was present between milkers on a farm or visits for a given milker ( $9 \%$ of total variation). However, a significant portion of the variation was attributed to the variation of contact time from one cow's milking to another by

Table 4. Distribution of number of milking units in 2 milking systems across 50 dairy herds in Ontario participating in a study on adoption and consistency of milking procedures

\begin{tabular}{lccc}
\hline Proportion of farms $(\%)$ & $<10$ units $/ 100$ cows & $10-16$ units $/ 100$ cows & $>16$ units/100 cows \\
\hline Parlor & 14 & 50 & 36 \\
Tie-stall & 26 & 62 & 12 \\
\hline
\end{tabular}


Table 5. Proportion of 50 farms that adopted recommended milking practices, visited during the summer of 2013

\begin{tabular}{lccc}
\hline Practice & No. of farms using practice, no. (\%) & Lower 95\% CI & Upper 95\% CI \\
\hline Use of premilking teat disinfection & $41(82)$ & 71 & 38 \\
Fore-stripping & $24(48)$ & 80 & 53 \\
Drying teats & $44(88)$ & 71 & 93 \\
Automatic takeoff use & $40(80)$ & - & 87 \\
Postmilking teat disinfection & $50(100)$ & - \\
\hline
\end{tabular}

a given milker and during a specific visit (44\% of total variation). Milkers therefore, did not equally prepare the different cows evaluated on a given visit; their routine was not uniform from one cow to another. It is important to note that for contact time, the effects of different milkers on one farm and the effect of visit number per milker on a farm could not be disentangled due to the structure of the data (cross-classified hierarchical model, Table 1). The effects of milker and visit were not nested within one another in this case. Nevertheless, relatively little variation in contact time could be attributed to the milker-visit combination.

Preparation Lag Time. The covariance parameter estimates for preparation lag time are presented in Table 8. The largest variation in preparation lag time was again attributed to differences between farms ( $40 \%$ of total variation), and to differences from one cow's milking to another on a specific visit (36\% of total variation). However, $21 \%$ of the total variation in preparation lag time could be attributed to differences between milkers on a given farm. Hence, all 3 of these sources of variation in preparation lag time were almost equally explained by differences between farms, between milkers, and across a cow's milkings. The variation between visits by a given milker on a farm was only a small part of the total variation (3\%). Hence, uniformity was observed in milkers from one day to another; however, it seemed the routine changed substantially from one milker to another, and from one cow to another, on a given day.

\section{Logistic Regression}

Contact Time. The results of the logistic regression analyses for adequate contact time are presented in Table 8. Of the 7 variables assessed in unconditional analyses, only the number of milking units per 100 cows was significantly associated with probability of a successful contact time. The odds of having adequate contact time were 3.66 times higher on farms with more than 16 units per 100 cows than on farms with less than 10 units per 100 cows $(P=0.03,95 \%$ CI 2.05-735.1; Table 9). The odds of having adequate contact time $(>30 \mathrm{~s})$ were 5.6 times higher in parlor herds than tiestall herds $(P=0.08,95 \%$ CI $0.78-39.88)$.

Preparation Lag Time. Of the variables assessed in the unconditional analyses, only number of milkers and adequate contact time were found to be significantly associated with preparation lag time $(P<$ 0.05 ; Table 10). The odds of farms having an adequate preparation lag time significantly increased when only one milker was present compared with 2 or more milkers $(P=0.01$; Table 10$)$. The odds of having adequate preparation lag were 3.9 times higher for milkings with adequate contact time than milkings with inadequate contact time $(P<0.01,95 \%$ CI 1.7-9.3). No other variables (milking system, forestripping, herd size, milker number, number of milking units, milker-to-unit ratio, number of units per 100 cows, or type of milking routine) were found to have a significant association with adequate preparation lag time.

\section{DISCUSSION}

Many studies have emphasized the importance of proper milking management and hygiene as a preventative measure for mastitis control on dairy farms (Barkema et al., 1998, 1999; Olde Riekerink et al., 2010; Dufour et al., 2011), yet few have described the variation in the daily application of these recommended practices at the farm level. Data used in the current analysis were from a study that aimed to determine potential risk factors for a rise in bulk tank milk SCC during the summer months (Shock, 2014). Consistent with previous literature, recommended milking practices measured (time premilking teat disinfectant was in contact with the

Table 6. Descriptive statistics for premilking teat disinfectant contact time (s) and preparation lag time (time between teat stimulation and milking unit attachment; s) in a group of 50 dairy herds from Ontario

\begin{tabular}{|c|c|c|c|c|c|c|c|c|}
\hline Variable & $\mathrm{N}$ & Mean & $\mathrm{SD}$ & Minimum & 1st quartile & Median & 3rd quartile & Maximum \\
\hline Preparation lag time $(\mathrm{s})$ & 1,446 & 123 & 89 & 0 & 65 & 102 & 156 & 743 \\
\hline
\end{tabular}


Table 7. Covariance parameter estimates for contact time in linear mixed null model of 50 Ontario dairy herds

\begin{tabular}{lcc}
\hline Variable & Estimate & Percent variance \\
\hline Farm & 0.1318 & 47 \\
Milker $\times$ visit number within farm & 0.0197 & 9 \\
Cow milking & 0.0544 & 44 \\
\hline
\end{tabular}

teats, teat stimulation, preparation-lag between udder preparation and unit attachment, and unit-on times) were not significantly different during either of the 2 visits, in herds with small seasonal SCC increases in the summer compared with herds with larger seasonal SCC increases (Shock, 2014). In a study by Hutton et al. (1990), researchers timed some of the recommended milking practices in a sample of 59 herds (classified as having either low or high SCC) from Washington State. The investigators found no difference in the frequency of the milking practices used by herds classified as low SCC compared with herds with high SCC. Hutton et al. (1990), however, did not reflect the consistency with which milkers on a single farm followed the milking protocol. Considerable variation is still likely in the implementation of many of the most important recommended milking practices. Based on the results of the
Table 8. Covariance parameter estimates for preparation lag time in linear mixed null model of 50 Ontario dairy herds

\begin{tabular}{lcc}
\hline Variable & Estimate & Percent variance \\
\hline Farm & 0.0479 & 40 \\
Milker within farm & 0.0262 & 21 \\
Visit within farm and milker & 0.0038 & 3 \\
Cow milking & 0.0440 & 36 \\
\hline
\end{tabular}

present study, most of the variation observed in the contact time for premilking disinfectants occurred at the farm level (Table 7). This was expected, as farmers use different premilking teat disinfectants, have different routines in place, and the order of these practices can vary from one farm to another. In the "adequate contact time" linear mixed model, the effects of milker and visit could not be disentangled from one another and not much variation was present from one milker to another across visits. This suggests that protocols on one farm are being consistently applied from one person to the next and that they are kept consistent over time. Nonetheless, considerable variation was still present from one cow to the next: milkers were not equally preparing all cows. It could be hypothesized this is due to individual cow cleanliness: cows with dirtier teats

Table 9. Unconditional associations between probability of a successful premilking teat disinfection contact time (defined as more than $30 \mathrm{~s}$ of disinfectant contact before wiping off) and various predictors hypothesized to be determinants of contact time success and estimated using a generalized mixed model with a logit link ${ }^{1}$

\begin{tabular}{|c|c|c|c|c|c|}
\hline Variable & Estimate & SE & Odds ratio & Odds ratio $95 \%$ CI & $P$-value \\
\hline Housing type & & & & & 0.08 \\
\hline Freestall & 1.72 & 1.00 & 5.6 & $0.78,39.8$ & \\
\hline Tie-stall & Referent & - & - & - & - \\
\hline Forestrip & & & & & 0.13 \\
\hline Yes & 1.55 & 1.02 & 4.7 & $0.64,35.0$ & \\
\hline No & Referent & - & - & - & - \\
\hline No. of milkers & & & & & 0.49 \\
\hline$>2$ & -0.72 & 1.29 & 4.7 & $0.22,98.6$ & \\
\hline 2 & -1.54 & 1.30 & 0.21 & $0.02,2.7$ & \\
\hline 1 & Referent & - & - & - & - \\
\hline No. of milking units & & & & & 0.85 \\
\hline$>12$ & -0.39 & 1.43 & 0.68 & $0.04,11.2$ & \\
\hline $6-12$ & 0.38 & 1.19 & 1.46 & $0.14,15.1$ & \\
\hline$<6$ & Referent & - & - & - & - \\
\hline Herd size (cows) & & & & & 0.14 \\
\hline$>83$ & -3.11 & 1.59 & 0.04 & $0.002,1.01$ & \\
\hline $42-83$ & -1.93 & 1.40 & 0.15 & $0.01,2.25$ & \\
\hline$<42$ & Referent & - & - & - & - \\
\hline Milking units per 100 cows & & & & & 0.03 \\
\hline$>16$ & 3.66 & 1.50 & $38.8^{\mathrm{a}}$ & $2.05,735.1$ & \\
\hline $10-16$ & 0.58 & 1.16 & $1.79^{\mathrm{b}}$ & $0.18,17.35$ & \\
\hline$<10$ & Referent & - & $\mathrm{c}^{\mathrm{c}}$ & - & - \\
\hline Milking units per milker & & & & & 0.50 \\
\hline$>6$ & 1.76 & 1.82 & 5.8 & $0.16,205.9$ & \\
\hline $2-6$ & 1.91 & 1.63 & 6.8 & $0.28,164.8$ & \\
\hline$<2$ & Referent & - & - & - & \\
\hline
\end{tabular}

${ }^{\mathrm{a}-\mathrm{c}}$ Within a given predictor, groups with different superscripts differed significantly $(P<0.05)$ after adjustment for multiple comparisons using the Tukey-Kramer method.

${ }^{1}$ Observations were obtained from a group of 41 herds from the province of Ontario. 
take more time to prepare than cows with clean teats and this affects the time milkers spend preparing other cows. Unfortunately, we could not test this hypothesis because we did not have cleanliness scores for the individual cows evaluated in this study. However, to ensure udder health and milk quality, producers should be aware of the importance of applying recommended milking practices for all cows, not just those that have visibly dirty udders and teat ends.

Having a correct and consistent milking routine is of importance for optimal milk letdown, and reducing variability could potentially affect production in a positive way (Rasmussen and Frimer, 1990; Hurnik, 1994). Milker consistency seems to have an important role in milk production. For example, Rasmussen and Frimer (1990) showed that, relative to a highly variable milking routine, cows with a consistent routine have higher milk yields. Hurnik (1994) also stressed the importance of keeping cow management consistent for increased milk yield and cow well-being. For optimal milk production and quality, milking management in herds should not only follow the recommended guidelines, but all milkers should also consistently apply them to all cows.

Milking system was also associated with adequate contact time, although it was not statistically significant $(P=0.08)$. The odds of having contact times over $30 \mathrm{~s}$ were 6 times greater in parlors than tie-stalls. This can be explained by the way milking routines are performed in each of the systems; in parlors, each step of the routine is applied to several cows at a time before moving onto the next step until unit attachment. In tiestalls, more variability is present in the way each cow is prepared and variability is also dependent on unit on-time of the previous cow as milking units are moved from one cow to another. In many tie-stall systems, the pattern of unit movement from one cow to another is highly variable.

The ratio of milking units per cow was also associated with the odds of having adequate contact time. Farms with more units per cow were more likely to have

Table 10. Unconditional associations between probability of a successful preparation lag time (defined as more than $60 \mathrm{~s}$ between first stimulation of teats and unit attachment) and various predictors hypothesized to be determinants of preparation lag time success and estimated using a generalized mixed model with a logit link ${ }^{1}$

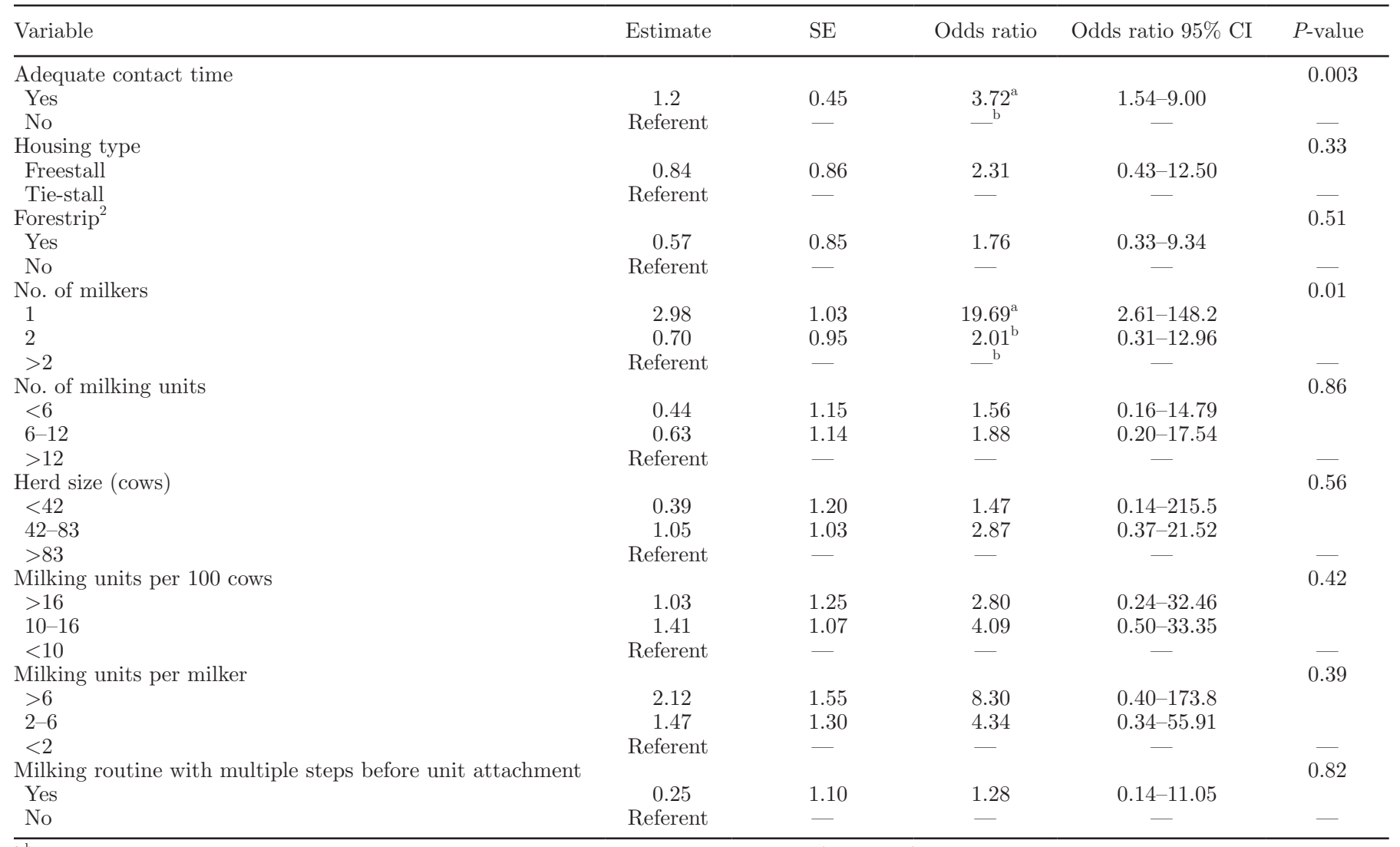

\footnotetext{
${ }^{a, b}$ Within a given predictor, groups with different superscripts differed significantly $(P<0.05)$ after adjustment for multiple comparisons using the Tukey-Kramer method.

${ }^{1}$ Observations were obtained from a group of 50 herds from the province of Ontario.

${ }^{2}$ Because of convergence issues, the analysis of the effect of forestripping on preparation lag time was run without using visit as a random effect.
} 
a contact time over $30 \mathrm{~s}$. The main difference observed was between farms with more than 16 milking units per 100 cows compared with farms with 10 to 16 units or with less than 10 units per 100 cows. Odds ratios should be interpreted with caution, as they were not very precise due to wide confidence interval; nonetheless, the association remains significant. Having more units available per cow may lead to more units becoming available quicker and also having a shorter total milking time. Milkers may feel less rushed to prepare cows if more units are available, instead of aiming for the fastest preparation to speed up unit on-time and be able to move on to the next cow. It is important to note that a higher proportion of parlor farms in this study had over 10 units per 100 cows, whereas tie-stall farms had a higher proportion of farms with less than 10 units per 100 cows (Table 4).

Of note, the assessment of contact time variation does not include farms that did not use a premilking teat disinfectant. Of the 50 study herds, 9 did not use a premilking teat disinfectant. Therefore, the current analysis and subsequent conclusions do not apply to almost $20 \%$ of the farms in this study. A similar lack of use of a premilking disinfectant was reported in a previous Canadian study, with $25 \%$ of herds not using a premilking teat disinfectant (Dufour et al., 2010). Lack of use of premilking teat disinfectant is sometimes seen in successful herds with good milk quality to reduce labor costs. However, in this instance the mean bulk tank SCC of herds not using premilking disinfectant was not significantly different from herds using premilking disinfectant; therefore, these herds did not have better or worse milk quality than their counterparts.

Based on the causal diagram, relationships between the variables milking system, herd size, number of people milking, number of units, and both outcomes of interest were hypothesized; surprisingly, only a few predictors were significantly associated with adequate contact time. Neither herd size nor number of people milking were associated with adequate contact time or preparation lag time in the present study; nevertheless, they have been observed to have a significant effect of bulk tank SCC levels (low vs. high; Shock, 2014). Hutton et al. (1990) also found that larger, more efficient herds (more cows milked per person per hour) had lower SCC levels than smaller herds. It could be that milkers on larger farms are more consistent or careful during the milking preparation; however, this hypothesis has not been tested. The lack of a herd size effect was likely due to a lack of variability in this characteristic in this data set. Most farms were smaller (average of 76 milking cows), with only one farm milking over 200 cows (Table 3). The generalizability of the results described here to larger herds is unknown and would merit further investigation. Similarly, the effect of nonfamily labor on milking consistency was not investigated, as the majority of farms in this study had family only involved during milking, which is also the case for the majority of Ontario dairy herds.

For preparation lag time, most of the variation was attributed to the variability between farms and between cow milkings. This analysis, however, also highlighted the substantial variability in the preparation lag time from one milker to another, and again this stresses the importance of informing people milking to apply the same procedures to all cow milkings. However, consistency was observed from one visit to another (low variability; Table 8). Milker consistency plays an essential role in both the correct implementation of recommended milking practices and the prevention of mastitis. Stup (2002) highlighted the importance of having standard operating procedures in place to reduce mastitis and milk quality problems, and to increase milk production on dairies. Similarly, Rasmussen et al. (1990) showed that, compared with cows milked using a variable milking routine, a standardized routine decreased the bulk tank bacterial count in the milk while increasing milk yield in cows. Although no difference was observed in the number of cases of clinical mastitis between the 2 groups studied, the standardization of the routine seemed to improve milk quality (Rasmussen et al., 1990).

Little variation in preparation lag was observed between visits; the farms and milkers in this data set seemed to be fairly consistent across time in applying this practice. This could be an important area to target in mastitis prevention, as it supports the assertion that producers are consistent in the application of milking procedures across time, regardless of whether or not they are correct. With corrective education and training, possible improvements in these practices could be experienced and maintained. By targeting farms where recommendations are not being followed properly, and encouraging change of milking procedures, it would be reasonable to hypothesize they would continue to follow the procedures consistently as they have before. Research has shown that most producers do not lack motivation to change, but rather lack information to make decisions leading to change (Jansen et al., 2010). By effectively communicating with milkers, advisors can hope to change their behavior and improve management practices (Jansen et al., 2010).

In univariable analyses, only contact time and number of milkers were associated with adequate preparation lag time (Table 10). Farms with adequate contact time were more likely to have an adequate preparation lag time compared with farms with nonadequate contact times. For farms using premilking disinfectant, contact 
time was included in preparation lag time (which was defined as the time from initial stimulation until unit attachment), so it is not surprising that milkings that met the 30-s cutoff for adequate contact time were more likely to meet the 60 -s cutoff for adequate preparation lag time. However, $20 \%$ of the farms in this study did not use premilking disinfectant and the majority (80\%) also met the recommended preparation lag time. The likelihood of having an adequate preparation lag time was not significantly different between farms with milking routines that involved more than a single step before unit attachment and farms where routines had a single step before unit attachment. Having a successful preparation lag time is not just dependent on having adequate contact time, but having an appropriate milking routine.

Farms with more than 2 milkers present at milking time were more likely to have a preparation lag time under $60 \mathrm{~s}$ compared with farms with only 1 or 2 milkers. Having more people at milking time tends to be associated with more rapid milkings and cows being prepared faster; however, having a lag time under 60 $\mathrm{s}$ can affect milk letdown and flow rates and increase milking unit on-time (Watters et al., 2012).

Farms in this study were selected based on a convenience sample (based on their likelihood to experience a rise in SCC during the summer; see Shock, 2014), potentially introducing a selection bias. In addition, farms were also not representative of the broader Canadian dairy farm population, as they were selected based on an SCC range that excluded herds with very low and very high cell counts; only herds that had a bulk tank SCC between 150,000 and 250,000 cells/mL during January 2013 were selected for the study. According to DFO, $58 \%$ of Ontario dairy herds typically fall in this range (DFO, 2015). Based on this sampling strategy, the inferences drawn from this study may not apply to herds with bulk tank SCC under 150,000 cells/ $\mathrm{mL}$ or greater than 250,000 cells/mL. Research shows that farmers who are defined as more proactive toward their practices are usually more informed and follow the regulations more closely relative to farmers considered as traditionalist or reclusive (Jansen et al., 2010). Participating producers could have been, in general, more compliant with recommended milking protocols than those producers that did not agree to participate.

No cow-milking-, visit-, or milker-specific measures were recorded during this study. All of the milking timings recorded were independent of the cow identification, and during the second visit, there was no intent to gather data from the same cows observed during the first visit. This could explain why a significant part of the variation was due to cow-to-cow variation. Some cow-milking level characteristics can affect the milking preparation timings (e.g., slower-milking cows, level of cow hygiene, cow temperament, position in the parlor or in the barn for tie-stall, and so on). Gathering some additional cow-milking-level measures, or using repeated measures for selected cows during the visits could have been useful to explain how cow-level or milkinglevel determinants affect the consistency and variability of the milking routine. Furthermore, the measure of preparation lag time was highly variable depending on each farm's routine. To accurately assess preparation lag time, it was defined as the time between the first contact with the teats (wiping, predipping, or start of forestripping) and cluster attachment.

Due to the exploratory nature of this study, the analyses focused only on unconditional associations. The effect of multiple predictors on adequate contact time and adequate preparation lag time would be worth investigating further with a data set comprised of a larger number of representative and heterogeneous farms. In such a data set, potential confounders could be controlled using conditional analyses. Likewise, this study only had a small number of visits performed: only 2 visits 1 mo apart. Even though our findings suggest farmers are consistent over time in the milking preparation routines, further studies should be conducted using a greater number of measurements (once a week or more) to better assess the variation across shorter time intervals covering a longer period of time.

\section{CONCLUSIONS}

The majority of farms in the study complied with the recommendations for adequate milking practices, which does not necessarily imply following a consistent timed protocol. This study shows several potential sources of variation in the milking routine on a dairy farm. Most farms were consistent over time in their milking preparation, and different milkers within a farm followed the same milking preparation routines regardless if they were correct or not. Determining whether correct milking protocols are being followed on farm or not can be a key area to target for improvement in mastitis control. If producers can be motivated to change and trained to implement a correct milking preparation routine, improvements in these practices could be experienced and maintained. Beyond farm level characteristics, important differences were observed from one cow to another during a given milking. Factors causing this variation should be further explored in future research.

\section{ACKNOWLEDGMENTS}

The authors thank John Wynands, Melissa Wagner, Gillian Marson, Erin Wynands, and Tai von Konigslow 
(all of University of Guelph) for gathering the information on the farm. Thanks also go to the participating producers for making this research possible. This project was part of the Canadian Bovine Mastitis and Milk Quality Research Network program, funded by Dairy Farmers of Canada and Agriculture and AgriFood Canada through the Dairy Research Cluster 2 Program, Dairy Farmers of Ontario (Mississauga, ON, Canada), the Ontario Veterinary College (University of Guelph), and the Ontario Ministry of Agriculture, Food and Rural Affairs. The first author (E.B.) was also supported by a Natural Science and Engineering Research Council of Canada -Collaborative Research and Training Experience Program (NSERC-CREATE) in milk quality scholarship.

\section{REFERENCES}

Barkema, H. W., Y. H. Schukken, T. J. G. M. Lam, M. L. Beiboer, G. Benedictus, and A. Brand. 1998. Management practices associated with low, medium, and high somatic cell counts in bulk milk. J. Dairy Sci. 81:1917-1927.

Barkema, H. W., J. D. Van der Ploeg, Y. H. Schukken, T. J. G. M. Lam, G. Benedictus, and A. Brand. 1999. Management style and its association with bulk milk somatic cell count and incidence rate of clinical mastitis. J. Dairy Sci. 82:1655-1663.

Barnouin, J., M. Chassagne, S. Bazin, and D. Boichard. 2004. Management practices from questionnaire surveys in herds with very low somatic cell score through a national mastitis program in France. J. Dairy Sci. 87:3989-3999.

Chassagne, M., J. Barnouin, and M. Le Guenic. 2005. Expert assessment study of milking and hygiene practices characterizing very low somatic cell score herds in France. J. Dairy Sci. 88:1909-1916.

DFO (Dairy Farmers of Ontario). 2015. Dairy Statistical Handbook 2014-2015. Accessed Jun. 8, 2016. https://www.milk.org/ Corporate/pdf/Publications-DairyStatsHandbook.pdf.

Dohoo, I. R., S. W. Martin, and H. Stryhn. 2009. Veterinary Epidemiologic Research. 2nd ed. VER Inc., Charlottetown, Prince Edward Island, Canada.
Dufour, S., H. W. Barkema, L. DesCôteaux, T. J. DeVries, I. R. Dohoo, K. Reyher, J. P. Roy, and D. T. Scholl. 2010. Development and validation of a bilingual questionnaire for measuring udder health management practices on dairy farms. Prev. Vet. Med. 95:74-85.

Dufour, S., A. Fréchette, H. W. Barkema, A. Mussell, and D. T. Scholl. 2011. Invited Review: Impact of udder health management practices on herd somatic cell count. J. Dairy Sci. 94:563-579.

Hurnik, J. F. 1994. An ethological approach to the management of dairy parlors. Proc. Natl. Mastitis Council Annual Meeting, Kansas City, MO. Natl. Mastitis. Counc. Inc., Madison, WI.

Hutton, C. T., L. K. Fox, and D. D. Hancock. 1990. Mastitis control practices: Differences between herds with high and low milk somatic cell counts. J. Dairy Sci. 73:1135-1143.

Jansen, J., C. D. M. Steuten, R. J. Renes, N. Aarts, and T. J. G. M. Lam. 2010. Debunking the myth of the hard-to-reach farmer: Effective communication on udder health. J. Dairy Sci. 93:1296-1306.

Köster, G., B. A. Tenhagen, N. Scheibe, and W. Heuwieser. 2006. Factors associated with high milk test day somatic cell counts in large dairy herds in Brandenburg. II. Milking practices. J. Vet. Med. A Physiol. Pathol. Clin. Med. 53:209-214.

NMC (National Mastitis Council). 2013. Recommended milking procedures. Accessed Jul. 13, 2015. http://www.nmconline.org/wpcontent/uploads/2016/09/Recommended-Milking-Procedures.pdf.

Olde Riekerink, R. G., M. Olde, H. W. Barkema, D. T. Scholl, D. E. Poole, and D. F. Kelton. 2010. Management practices associated with the bulk-milk prevalence of Staphylococcus aureus in Canadian dairy farms. Prev. Vet. Med. 97:20-28.

Rasmussen, M. D., and E. S. Frimer. 1990. The advantage in milking cows with a standard milking routine. J. Dairy Sci. 73:3472-3480.

Rasmussen, M. D., E. S. Frimer, Z. Horvath, and N. E. Jensen. 1990. Comparison of a standardized and variable milking routine. J. Dairy Sci. 73:3472-3480.

Shock, D. A. 2014. An epidemiologic study of the summer rise in bulk milk somatic cell count in Ontario dairy herds. $\mathrm{PhD}$ Thesis, Department of Population Medicine, University of Guelph, Guelph, Ontario, Canada.

Stup, R. 2002. Standard operating procedures: Managing the human variables. Page 11 in Natl. Mastitis Counc. Reg. Mtg. Proc., Syracuse, NY. Natl. Mastitis Counc. Inc., Madison, WI.

Watters, R. D., N. Schuring, H. N. Erb, Y. H. Schukken, and D. M. Galton. 2012. The effect of premilking udder preparation on Holstein cows milked 3 times daily. J. Dairy Sci. 95:1170-1176. 